\title{
ОСОБЕННОСТИ СОЦИАЛЬНЫХ ТРАНСФОРМАЦИЙ В СИСТЕМЕ ОБРАЗОВАНИЯ
}

\section{FEATURES \\ OF SOCIAL TRANSFORMATIONS IN THE EDUCATION SYSTEM}

\section{P. Rostovtseva}

Summary: The article considers the typical features of social transformations taking place in modern society. The author defines this society by the term "knowledge society», and also describes the role and significance of the Internet technologies in the development of social processes. A modern view of University education in the global world is given.

Keywords: knowledge society, social transformations, University environment, interdisciplinary knowledge.
Ростовцева Полина Петровна

К.п.н., доцент, ФГБОУ ВО «Финансовый университет при Правительстве Российской Федерации» (г. Москва) Rostovtseva_75@mail.ru

Аннотация: Статья посвящена характерным особенностям социальных трансформаций, происходящих в современном обществе. Автор определяет данное общество термином «общество знания», а также рассматривает роль и значения интернет технологий в развитии общественных процессов. Приводится современный взгляд на университетское образование в глобальном мире.

Ключевые слова: общество знания, социальные трансформации, университетская среда, междисциплинарные знания

профессиональных. Возрастание социальной роли научного знания, новых возможностей усовершенствования экономики на основе технического прогресса одни исследователи обосновывали особой ролью инженерных кадров, а также несоответствием между прогрессом технологий и темпами модернизации социально-культурной сферы и ее институтов. Другая группа исследователей утверждала, что технический прогресс и инвестиции в образование и науку являются приоритетными предпосылками развития общества, где ведущая роль отводится организованным знаниям. Предполагается перераспределение акцента власти в социуме, так как грань между индустриальной системой, бизнесом и государством всё более уравнивается $[2,10]$. Совместная профессиональная деятельность специалистов в рамках постиндустриального развития становится решающим условием планирования и принятия решения, обеспечивающего развитие производства и социума.

Проблематика новой социальной значимости научного знания, а также его влияния на процессы социально-культурной трансформации в целом, была интегрирована в новый теоретический контекст концепции постиндустриального общества, которое:

- стабилизирует функцию науки и знания как приоритетной институциональной ценности в обществе;

- делает принятия решений более техничным, все более вовлекаются ученые, квалифицированные специалисты в общественный и политический процессы;

- усиливает наличествующие тенденции бюрокра- 
тии в системе интеллектуального труда, изменяет традиционные определения интеллектуальных интересов и ценностей;

- актуализирует проблему взаимоотношения технического и гуманитарного интеллекта [1].

Развитие представлений об обществе знания определило проблему поиска критериев разграничения между представлениями и другими концепциями социальных трансформаций. Концепции информационного общества и общества знания выступают как теоретические построения, определяющие, как качественная социально-культурная трансформация в современном мире связана с ролью информации и знания, и местом человека в этих трансформациях.

В этих обстоятельствах, когда интегрированы социальные трансформации и становление общества знания совершается, наука обретает ряд новых качеств и функций. Научные исследования определяются не внутренне научными, а заданными извне, социальными и политическими целями, когда ученые, политики, представители промышленности взаимодействуют с целью определения проблемы, исследовательской стратегии и нахождения решения. Это можно охарактеризовать как перевод политических целей в технические и исследовательские стратегии. Процесс диффузии дискурсов науки, политики и общества следует интерпретировать как «сциентификацию общества» и «политизацию науки».

Качественные изменения во взаимоотношениях науки и общества получили признание, особенно в том, что основной характеристикой научного знания становится развитие его социальных и политических черт, постепенно стираются линии дифференциации науки, социального общества и культуры; проявляется трансформация выстраивания взаимосвязей между данными феноменами. Практическая реализация научного знания предполагает не только поиск основополагающих законов природы, а также поиск фундаментальных законов образования как транслятора научных, культурных ценностей, что в большей степени проявляется как процесс, детерминируемый сущностью применения знания, представлениями о социальном запросе и интересах потребителей.

Перенос результатов образования, научных исследований в сферу социальных потребностей интенсифицируется адекватно современным средствам коммуникации и актуализирующийся мобильности социального интеллектуального потенциала. Помимо этого, реализуется трансляция результатов образования посредством электронных средств массовой информации, международных институтов, многосторонних коммуникативных механизмов, сетевых структур гражданского общества.
Непосредственно система образования, наука, детерминируя процесс осознания и одобрения социально значимых решений, предоставляет возможность понять границы неопределенности в развитии, так как недостаток реального подтвержденного знания стремится компенсировать посредством применения различных способов статистической обработки информации, моделированием процессов, задействованием гипотетического подхода к анализу данных, а в итоге - образование теряет ценностный смысл. Недостаток гипотетических теорий и идей отражается в конфликтах между исследователями, что приводит к расшатыванию авторитетности, как науки, так и образования. Ценность научного анализа начинает девальвироваться.

В этих условиях публикации и рассуждения, посвященные решающей роли знания, образования в экономической и социальной организации общества оказались весьма востребованными, даже при условии, что исследователи не сходились во мнениях по ряду вопросов.

Развитие информационно-коммуникационных технологий, комплекс современных социально-экономических феноменов, достижения в области технологий, государственные стандарты, детерминирующие процесс производства, модернизация и адаптация информационных ресурсов, актуализация новых принципов социального управления и организации являются вызовами, которые актуализируют инновационные процессы в системе образования. Концепция профессионального образования отвечает на вызовы и основывается на системной подготовке когнитивного специалиста, который становится самопредпринимателем, или предпринимателем в рамках индивидуальной рабочей силы [6].

Для победы или даже элементарного выживания в такой глобализованной экономике, образование должно трансформироваться в специфически другое образование, где проекты исследования, разработки стали содержательной сущностью образовательных программ в университетах и лабораториях, где готовится нового рода специалист. В отличие от специалиста традиционной индустриальной эры, от него требуется компьютерная грамотность, натренированность в обработке информации, в применении и создании алгоритмов, в установлении необходимого симулирования [11]. Но на практике этого оказывается недостаточным. Чтобы конкретная и нужная инновация стала действенной, очень важно воспользоваться умениями компьютерных специалистов, расчетчиков-инженеров, экспертов в области естественных наук. Все это дает нам огромный объем междисциплинарных знаний, необходимых для развития экономики на этой стадии ее развития.

Согласно докладу специализированного учреждения 
Организации Объединённых Наций по вопросам образования, науки и культуры (ЮНЕСКО) «общество знания» значительное рассматривается в так называемой электронной, или цифровой педагогике. На сегодняшний день электронная педагогика - это относительно новый и непривычный термин, объясняющий в значительной мере сферу применения с использованием самых последних информационно-коммуникационных технологий в образовательном процессе, в формировании личности, ее взаимодействия в обществе, структурами гражданского общества, в сфере экономики, техники, производства, науки, культуры [9].

В условиях нового технологичного развития, главным компонентом которого является устойчивое распределение, персонификация и сближение различных ИКТ, эти процессы начинают значительно угрожать стандартным формам лично-ориентированного основания педагогики. Наиболее уязвимыми являются педагогические проблемы, которые основаны на степени ограничения и прямого контроля информационных потоков. У системы образования все меньше остается «охранной грамоты» хотя бы потому, что информационный бум играет все большую роль в факторах и наличии самоограничения, управления информационными потоками.

В качестве средства привлечения всемирная сеть Интернет и другие ИКТ могут выступать в роли самых различных весомых источников влияния, в том числе для тех, кто отвергает ценностные ориентиры современной системы образования. Необходимо также отметить, что уже в ближайшее время портрет «обычного» пользователя, или современного студента, или молодого человека, появившегося на свет в эпоху процветания Интернета, будет меняться. Выравнивание возможностей в этом виртуальном мире, о котором так вдохновенно говорят, на поверку оказывается устранением последних преград глобальной коммуникации, которое прежде сдерживалось традиционной национальной культурой. Это в итоге приводит к тому, что социальные трансформации, особенно в системе образования, все в большей степени перенесутся в киберпространство, и достижение социального порядка, трансляция культурных ценностей в условиях взаимодействия множества индивидов, имеющих разнонаправленные интересы, становится проблемой сетевой коммуникации. В системе образования новый скачок в развитии ИКТ вызывает столкновение между очередным расширением технических возможностей человечества и прорывом в свободу применения информационных технологий, без ограничения, без контроля и полномочий человека.

Помимо этого, испытанию подвергнется и другая точка зрения, считающая культуру самым влиятельным определителем мощнейших политических процессов, влияние которой может быть умножено или уменьшено, но не заменено разрастающимся действием технологий [7].

Решение этого противоречия заключается в раскрытии механизмов модернизации системы образования в условиях необходимости определения четких перспектив ее развития, набора эмпирических индикаторов. На основании этого можно сделать вывод, что образовательная система инновационна, способна ответить на вывозы глобальной информационной цивилизации общества знаний.

Инновационно-опережающее содержание образования, его формирование, поверка и стабилизация фундамента знаний подразумевает высокий уровень человеческого интеллекта, необходимость пополнять его непрерывным вводом научных исследований, экспериментов и знаний [8]. Этот тезис не нуждается в каком-то подтверждении, поскольку нельзя не согласиться, что инженерные и технологичные сферы - это такие области, в которых интеллект, креативность и изобретательность являются системообразующими. Проблема в том, насколько система формирования личности специалиста, его компетентности, способов и технологий познания приведет к потере большинства способностей людей, которые уже сейчас постепенно отходят на задний план и становятся серьезной потерей для человечества. Несомненно, напрашивается вывод, что пренебрежение развитием тех общих умений и навыков, которые создаются не на специальное использование, а формируют интеллектуально зрелую личность, является неправильным и ненужным [7]. Продвижение информационных систем должно подчеркивать тот факт, что они были, являются и остаются инструментарием для получения человеческих знаний. Помимо этого, они служат ориентиром для человеческих решений, но, к сожалению, не могут выступать в качестве замены интуиции, математических, экономических, управленческих, социальных и т.д. способностей, которые должны терпеливо воспитываться личным энтузиазмом, ответственностью, тренировкой и размышлением.

Кризис в экономике, случившийся недавно в мире затронул и Соединенные Штаты Америки - страну, где ИКТ высокоразвиты, достаточно разработаны передовые экономические теории, симуляции и компьютерное моделирование. Эта рецессия была вызвана в большой степени нехваткой чувства персональной ответственности и морального удовлетворения крупных финансовых менеджеров. Это свидетельствует о том, что огромное количество факторов общественной и частной жизни имеет место быть. Этими факторами являются человеческие ценности, нравственные принципы, идеалы, модели построения личности гражданина, справедливого общества, распределения благ и возможностей. Также к ним относится стандарт жизни, создающий необходи- 
мые условия для укрепления человеческого достоинства и уважения к главным правам человека, которые невозможно включить в описание каких-либо технических инструкций. Все эти факторы не являются личными предпочтениями или склонностями, они показывают наиболее характерные признаки внутренней сущности и универсальной целостности любой культуры в ходе ее развития и всей истории человечества. С точки зрения возможности их межкультурной значимости факторы следует изучать, исследовать, критически оценивать и обсуждать, сопоставлять друг с другом, придать значение в их культурном контексте. Они могут выражаться в разных формах - философии, истории, в формах изобразительных искусств, музыки, мировоззрениях и истолкованиях человеческой жизни. Все это и составляет ту область знания, знакомство, с содержанием которого влияют на чувственное восприятие через непосредственные контакты и общение и воспринимаются лучше без информационных технологий. Эта обширная область знания традиционно подразделялась на значительное количество специальных дисциплин, которые для краткости получили название «гуманитарные науки». Гуманитарные науки в течение многих лет были в составе учебных планов средних и высших школ, университетов и академий, научных школ, но сегодня они в малой доле входят в университетское образование, а потому лишаются поддержки, особенно когда представляется необходимым оптимизировать затраты, урезают то, что не влияет непосредственно на экономический рост.

Можно сделать вывод, что такая превалирующая направленность обозначает ценность только тех знаний или такой деятельности, которые могут считаться «продуктивными». К примеру, математические вычисления могут быть «полезными», так как могут служить основой для дальнейшей деятельности в любой сфере. Также считается, что философия или литература может быть «лишней», поскольку не влияет на экономический рост любой страны. Но именно такое восприятие дисциплин приводит к грубейшим ошибкам в международной политике за последние годы. Несомненно, глобализация всего мирового пространства потребует более глубокого восприятия культурных различий, и, именно, исторические, философские, религиозные и социальные знания будут важны. Сегодня понятие самореализации у культурной личности с богатым внутренним миром, высоким творческим потенциалом, устойчивым научным мировоззрением соответствует понятию счастья и удовлетворения всех личных, финансовых и социальных потребностей человека [4]. Культивирование дисциплин и видов деятельности, о которых идет речь, вносит существенный вклад в личностное развитие и совершенствование человека. Наступает время для пересмотра сущности человека. Это выводит «человековедение» как синтетическое учение на новый уровень. Современное общество, при решении экономических, социальных и политических проблем, нуждается в пересмотре человеческих и общественных ценностей. Основной задачей становится понимание собственного предназначения в мире и дальнейшее развитие научно-технической цивилизации общества знаний. Человек выступает в роли ведущего в обществе, он сочетает в себе природное, общественное и индивидуальное, субъективированное качество $[3,13]$.

Социальные науки изучают общество как фактор, формирующий и определяющий становление и развитие личности, как взаимоотношение в системе «человек-общество», так и в системе «общество-человек». Взаимоотношения «человек-общество» рассматривают проблемы отношения человека с различными формами общества, с различными социальными общностями людей (страна, нация и т.д.), с различными социальными институтами, с различными формами общественного сознания и духа. Взаимоотношения «общество-человек» рассматривают проблемы общества, различных социальных общностей людей (страна, нация и т.д.), различных социальных институтов с отдельным индивидуумом. Но сейчас очень важно определить человеческую индивидуальность, его самоценность. Принадлежность к данной системе определяет право каждого человека и его моральный долг возлагать на себя свою часть общечеловеческой ответственности, создавая при этом личную ноосферу, персонифицированного понятия жизни, актуализации проблем саморефлексии и самосознания главного понимания смысла жизни. В информационнообразовательной среде общества человек принимает субъет-субъектные отношения и выступает в качестве лидера социально-культурного процесса.

«Опыт показывает, что при грамотной постановке задачи, а также профессиональной реализации проектов информатизации высвобождаются значительные временные, человеческие и прочие ресурсы. На наш взгляд, главное следствие для учителя при этом заключается в возможности уделять больше времени и усилий для качественного наполнения образовательного процесса, решения содержательных задач современной педагогики, осмысления своей социальной роли» [5].

\section{ЛИТЕРАТУРА}

1. Белл Д. Грядущее постиндустриальное общество. Опыт социального прогнозирования. - М., 1999. - С.57.

2. Белогаш М.А., Мельничук М.В. Новая парадигма лидерства в высшем образовании // Мир науки, культуры, образования. 2019 . № 4 (77). С. $253-256$. 
3. Бехманн Г. Концепции информационного общества и социальная роль информации // Политическая наука. - 2008. - №2. - C.28

4. Виландберг А.А. Представление учебной информации в высокотехнологичной образовательной среде // Научное мнение. 2012. №9. С. 120-124.

5. Всемирная инициатива Microsoft «Партнерство в образовании» - в России. Итоги реализации. Первый этап 2004-2008 годы. [Электронный ресурс]. URL: http://www.microsoft.com/Rus/Education/.

6. Гусейнова И.А Сопряжение системы высшего образования сферы труда // Вестник Московского государственного лингвистического университета. Серия: Образование и педагогические науки. 2019.№1 (830).

7. Замалеев А.Ф. «Новая порода людей», или философия воспитания эпохи русского Просвещения // Вестник Санкт-Петербургского университета. 2013. Серия 17. Выпуск 2. С. 90-97

8. К Клочко В.Е., Краснорядцева 0.М. Особенности операционализации понятия «инновационный потенциал личности» // Вестник ТГУ. 2010. №339. С. 151154.

9. К обществам знания. Всемирный доклад ЮНЕСКО. - Париж: Изд-во ЮНЕСКО, 2005. - С.141.

10. Крипон Н.С. ИКТ как условие развития ценностных ориентаций студентов ВУЗа в процессе обучения // Новые исследования в разработке техники и технологий. 2016. №1. С.4-6.

11. Швецов А.Н. Роль государства в преобразовании социоэкономического пространства // Пространственная экономика. 2015. №1. С. 38-61.

12. Calvert S.L., Rideout V.J., Woolard J.L., Barr R.F., Strouse G.A. (2005). Age, ethnicity, and socioeconomic patterns in early computer use. American Behavioral Scientist, 48(5), 590-607.

13. Gruzina Yu.M., Melnichuk M.V., Belogash M.A. Leadership ideas shaped by digital insights in higher education // Управленческие науки. 2019. Т. 9. № 4. С. 75-84.

(c) Ростовцева Полина Петровна (Rostovtseva_75@mail.ru).

Журнал «Современная наука: актуальные проблемы теории и практики»

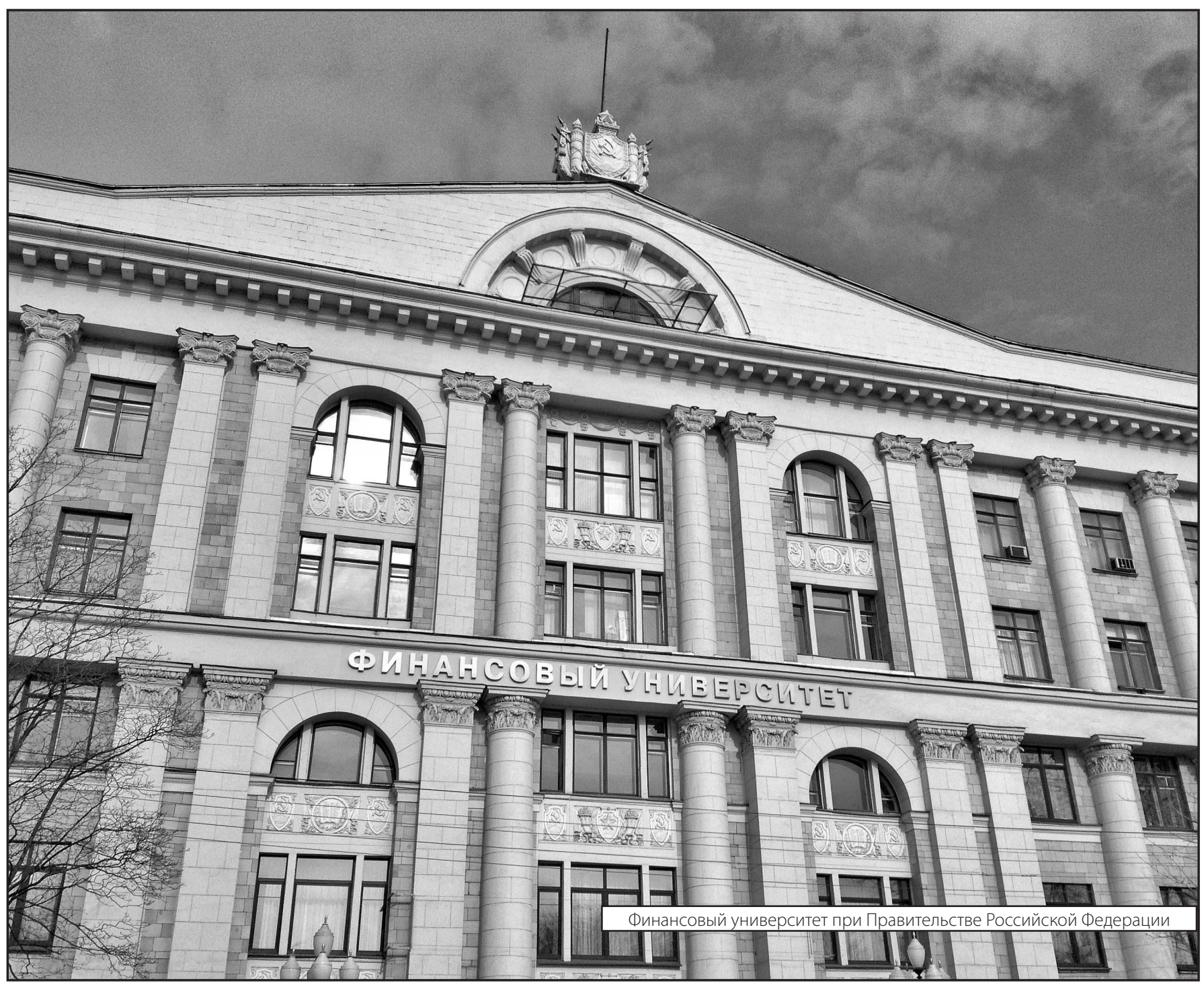

